\title{
Mitral Valve Annuloplasty with a Homemade Single-sized Polytetrafluoroethylene Band in Degenerative Mitral Regurgitation Mohamed Azzam*1, Ahmed Fakhry ${ }^{2}$, Ahmed Nabil Khallaf ${ }^{3}$, Hesham Zayed Saleh ${ }^{1}$ \\ ${ }^{1}$ Department of Cardiothoracic Surgery, Faculty of Medicine, Cairo University, Egypt \\ ${ }^{2}$ Department of Cardiothoracic Surgery, Faculty of Medicine, Beni-Suef University, Egypt \\ ${ }^{3}$ Department of Cardiothoracic Surgery, Faculty of Medicine, Fayoum University, Egypt \\ *Corresponding author: Mohamed Azzam, Mobile: (+20) 01001427368, E-mail: dr.mohamed.ezzazzam@ gmail.com
}

\begin{abstract}
Background: Although mitral annuloplasty is an essential component of mitral repair, there remains little agreement on the ideal device to be used or the ideal sizing method.

Objectives: The purpose of this study was to report the early clinical and echocardiographic outcomes of patients undergoing repair for degenerative mitral regurgitation using a homemade single-sized $(65 \mathrm{~mm})$ Polytetrafluoroethylene band, and comparing it to the use of commercially available complete rigid rings.

Patients and methods: This is a retrospective study including 106 patients, who underwent mitral repair for degenerative mitral regurgitation at Cairo University Hospitals between February 2013 and July 2019. These patients were divided into 2 groups. Group (A) included 69 patients who underwent repair with a single-sized band, and group (B) included 37 patients whose repair included the use of a commercial rigid ring. The primary endpoint was freedom from significant mitral regurgitation at one-year follow-up. Secondary endpoints included mean mitral valve gradient measured postoperatively, and freedom from reoperation at one year.

Results: There was no statistically significant difference between both groups in any of the above-mentioned endpoints being examined.

Conclusion: The use of a single-sized Polytetrafluoroethylene band for annuloplasty in degenerative mitral disease showed satisfactory results comparable to the commercial rigid rings. Further studies with longer follow-up are needed to confirm the durability of mitral repair using this technique.
\end{abstract}

Keywords: Mitral regurgitation, Mitral repair, Annuloplsty.

\section{INTRODUCTION}

Since the introduction of mitral repair for the treatment of mitral regurgitation (MR), mitral valve annuloplasty was deemed an integral part of valve repair, especially in cases of degenerative mitral disease ${ }^{(\mathbf{1})}$.

Annuloplasty not only restores the shape of the mitral annulus but was also proven by various groups to improve the durability of the repair ${ }^{(2,3)}$.

In many studies, the type of annuloplasty device used flexible or rigid and complete or partial seemed to have little impact on the clinical outcomes of the repair, in patients operated for degenerative mitral insufficiency ${ }^{(4-6)}$.

Given the expense added by the use of a ring, many groups have tried less expensive annuloplasty alternatives. These included Dacron bands, polytetrafluoroethylene (PTFE) bands, and pericardial bands. Trying such alternatives was met with variable degrees of success ${ }^{(7-9)}$.

In the setting of developing countries with relatively limited financial resources such an alternative is worth exploring.

The purpose of this study was to report the early clinical and echocardiographic outcomes of patients undergoing repair for degenerative MR using homemade fixed length PTFE bands, and comparing them to patients who underwent repair using commercially available complete rigid rings.

\section{PATIENTS AND METHODS}

This retrospective observational study included a total of 106 patients who underwent first-time mitral valve repair for degenerative mitral valve disease, at the Cardiothoracic Surgery Department of Cairo University Hospitals, in the period between February 2013 and July 2019. During this period, a total of 119 patients underwent mitral repair.

Exclusion criteria: Previous open heart surgery, rheumatic pathology found intraoperatively, concomitant coronary artery bypass grafting, left ventricular ejection fraction less than $40 \%$, or incomplete data in individual clinical files. The remaining 106 patients were included in the study and their individual files were reviewed to extract clinical, operative and outcome data.

Ethical Consideration: The study was approved by the Local Ethical Committee of Cairo University. Written consent was obtained from every patient prior to the procedures. This work has been carried out in accordance with the code of Ethics of the World Medical Association (Declaration of Helsinki) for studies involving humans.

\section{Study Groups:}

All patients in the study had severe MR, with obvious degenerative or myxomatous features on 
preoperative transthoracic echocardiography. The choice between commercial ring and PTFE band annuloplasty was subject to surgeon's preference and ring availability. Commercial rings used included Carpentier-Edwards Physio ring (Edwards Life sciences, Irving, CA, USA) and Medtronic CG Future annuloplasty ring (Medtronic, Inc, Minneapolis, Minn, USA). These were used in 37 patients. PTFE annuloplasty band was used in the remaining 69 patients. Echocardiography was repeated prior to discharge from the hospital for all surviving patients. A follow-up visit was arranged one year after the procedure, and patients were assessed clinically and echocardiographically. The follow-up was completed in 91 patients $(88.3 \%$ of surviving patients). MR on postoperative echocardiography was graded in a semi-quantitative fashion depending on regurgitant jet area. This was classified as none or trivial $\left(0-2 \mathrm{~cm}^{2}\right)$, mild $\left(2-4 \mathrm{~cm}^{2}\right)$, moderate $\left(4-8 \mathrm{~cm}^{2}\right)$, or severe (more than $\left.8 \mathrm{~cm}^{2}\right){ }^{(10)}$.

\section{Outcomes of interest:}

The primary endpoint being examined was freedom from moderate or more MR at one-year follow-up. Secondary endpoints included mean mitral valve gradient as measured postoperatively, and freedom from reoperation at one year.

\section{Operative Technique:}

All surgeries were performed through a median sternotomy, with aorto-bicaval cannulation. Myocardial protection was ensured through cold blood cardioplegia, moderate hypothermia and topical ice slush. The mitral valve was approached through a left atriotomy. The repair procedure was started by placing the interrupted 2-0 braided sutures, either alongside the entire circumference of the mitral annulus in case a ring was used, or from trigone to trigone along the posterior annulus in case a PTFE band was used. This was followed by careful assessment of the mitral valve pathology and subsequent repair of any prolapsing segments. At the conclusion of the repair, an intraoperative ring sizer was used to determine the size of the mitral ring to be used. In case a PTFE band was to be used, the band was fashioned using a strip of PTFE $10 \mathrm{~mm}$ in width folded twice on itself to form a trilayered band $3 \mathrm{~mm}$ in width, which is held between two hemostats at the edges and one more hemostat at the center. This helps adding substance to the band, preventing excessive crumpling as the sutures are tied. The band was made to be of a fixed length of $65 \mathrm{~mm}$.

\section{Statistical Analysis}

Data were analyzed using the statistical package for social sciences, version 20.0 (SPSS Inc., Chicago, Illinois, USA). Continuous variables were expressed as mean \pm standard deviation (SD). Categorical variables were expressed as numbers and percentages. Comparison of quantitative variables was done using student- $t$ test while comparison of categorical data was done using Chi-square test $\left(\mathrm{X}^{2}\right)$. A difference was considered significant when $\mathrm{p}<0.05$.

\section{RESULTS}

Table (1) outlined the preoperative characteristics of the patients. Both groups were comparable except for a statistically significant higher incidence of hypertension in group (B). The higher incidence of atrial fibrillation and pulmonary hypertension in both groups denotes a relatively delayed referral for surgery.

Table (2) outlined the operative characteristics of patients with no statistically significant difference between groups. Of note was one incidence of systolic anterior motion (SAM) in group B which responded to conservative management without the need for any surgical revision.

Table (3) outlined the early outcomes of surgery with comparable results between both groups. Despite the fixed size band used in group (A) irrespective of patient sex or weight, the transvalvular gradient was comparable between both groups on postoperative echocardiography.

At follow-up there was significant improvement in NYHA class in both groups. There was only one patient in group (A) who required reoperation. He was reoperated 5 months postoperatively, due to Gortex neochord tearing through the substance of the anterior leaflet (Table 4).

Table (1): Preoperative characteristics

\begin{tabular}{|l|c|c|c|}
\hline & $\begin{array}{c}\text { PTFE } \\
\text { Band } \\
(\mathbf{N = 6 9 )}\end{array}$ & $\begin{array}{c}\text { Commercial } \\
\text { ring } \\
(\mathbf{N}=37)\end{array}$ & P-value \\
\hline Age (years) & $\begin{array}{c}43.9 \pm \\
12.8\end{array}$ & $42.2 \pm 10.1$ & NS \\
\hline Female & $\begin{array}{c}41 \\
(59.4 \%)\end{array}$ & $23(62.1 \%)$ & NS \\
\hline Height (cm) & $\begin{array}{c}162 \pm \\
11.1\end{array}$ & $160 \pm 12.5$ & NS \\
\hline Weight (kg) & $\begin{array}{c}59.1 \pm \\
9.7\end{array}$ & $58.7 \pm 10.3$ & NS \\
\hline NYHA (III- & $\begin{array}{c}49 \\
(71.0 \%)\end{array}$ & $25(67.5 \%)$ & NS \\
IV) & $\begin{array}{c}10 \\
(14.4 \%)\end{array}$ & $6(16.2 \%)$ & NS \\
\hline Diabetes & 11 & $12(32.4 \%)$ & $<0.05$ \\
\hline Hypertension & $(15.9 \%)$ & & \\
\hline Atrial & $\begin{array}{c}26 \\
(37.6 \%)\end{array}$ & $13(35.1 \%)$ & NS \\
Fibrillation & $56.1 \pm$ & $54.0 \pm 3.2$ & NS \\
\hline Ejection & 3.9 & & \\
\hline Fraction (\%) & $48.5 \pm$ & $45.1 \pm 12.8$ & NS \\
\hline PAP & 11.6 & & \\
\hline & & & \\
\hline
\end{tabular}


Table (2): Operative characteristics

\begin{tabular}{|c|c|c|c|}
\hline & $\begin{array}{l}\text { PTFE } \\
\text { Band } \\
(\mathrm{N}=69)\end{array}$ & $\begin{array}{c}\text { Commercial } \\
\text { ring } \\
(\mathbf{N}=37) \\
\end{array}$ & $\begin{array}{c}P- \\
\text { value }\end{array}$ \\
\hline $\begin{array}{l}\text { Repair: } \\
\text { Annuloplasty alone } \\
\text { Segmental resection } \\
\text { Neochords } \\
\text { Commissuroplasty }\end{array}$ & $\mid \begin{array}{c}18(26.0 \%) \\
44(63.7 \%) \\
9(13 \%) \\
1(1.4 \%)\end{array}$ & $\begin{array}{c}10(27 \%) \\
23(62 \%) \\
6(16.2 \%) \\
1(2.7 \%)\end{array}$ & NS \\
\hline $\begin{array}{l}\text { Associated } \\
\text { procedure: } \\
\text { - AVR } \\
\text { - Tricuspid repair } \\
\text { - PFO closure } \\
\text { - LAA closure } \\
\end{array}$ & $\begin{aligned} 2 & (2.9 \%) \\
20 & (28.9 \%) \\
1 & (1.4 \%) \\
21 & (30.4 \%)\end{aligned}$ & $\begin{array}{c}1(2.7 \%) \\
11(29.7 \%) \\
0(0 \%) \\
10(27.0 \%)\end{array}$ & NS \\
\hline $\mathrm{X}$-clamp time & $\begin{array}{c}92.3 \pm \\
16.8 \\
\end{array}$ & $97.1 \pm 14.5$ & NS \\
\hline Total CPB time & $\begin{array}{c}133 \pm \\
21.1 \\
\end{array}$ & $141 \pm 18.3$ & NS \\
\hline $\begin{array}{l}\text { Systolic anterior } \\
\text { motion }\end{array}$ & $0(0 \%)$ & $1(2.7 \%)$ & NS \\
\hline
\end{tabular}

Table (3): Early outcomes

\begin{tabular}{|l|c|c|c|}
\hline & $\begin{array}{c}\text { PTFE } \\
\text { Band } \\
(\mathbf{N = 6 9 )}\end{array}$ & $\begin{array}{c}\text { Commercial } \\
\text { ring } \\
(\mathbf{N}=37)\end{array}$ & $\begin{array}{c}\boldsymbol{P} \text { - } \\
\text { value }\end{array}$ \\
\hline Mortality & $2(2.9 \%)$ & $1(2.7 \%)$ & $\mathrm{NS}$ \\
\hline Stroke & $0(0 \%)$ & $1(2.7 \%)$ & $\mathrm{NS}$ \\
\hline Wound infection & $1(1.4 \%)$ & $1(2.7 \%)$ & $\mathrm{NS}$ \\
\hline $\begin{array}{l}\text { Re-exploration } \\
\text { for bleeding }\end{array}$ & $3(4.3 \%)$ & $2(5.4 \%)$ & $\mathrm{NS}$ \\
\hline Renal failure & $1(1.4 \%)$ & $0(0 \%)$ & $\mathrm{NS}$ \\
\hline $\begin{array}{l}\text { Permanent Heart } \\
\text { block }\end{array}$ & $0(0 \%)$ & $1(2.7 \%)$ & $\mathrm{NS}$ \\
\hline $\begin{array}{l}\text { Mean Mitral } \\
\text { gradient }\end{array}$ & $3.4 \pm 0.6$ & $3.1 \pm 0.8$ & $\mathrm{NS}$ \\
\hline
\end{tabular}

Table (4): Follow-up data

\begin{tabular}{|l|c|c|c|}
\hline & $\begin{array}{c}\text { PTFE } \\
\text { Band } \\
(\mathbf{N}=59)\end{array}$ & $\begin{array}{c}\text { Commercial } \\
\text { ring } \\
(\mathbf{N}=\mathbf{3 2})\end{array}$ & $\begin{array}{c}\boldsymbol{P} \text { - } \\
\text { value }\end{array}$ \\
\hline $\begin{array}{l}\text { NYHA } \\
\text { (III-IV) }\end{array}$ & $2(3.3 \%)$ & $1(3.1 \%)$ & NS \\
\hline $\begin{array}{l}\text { Significant } \\
\text { MR }\end{array}$ & $1(1.7 \%)$ & $1(3.1 \%)$ & NS \\
\hline Reoperation & $1(1.7 \%)$ & $0(0 \%)$ & NS \\
\hline
\end{tabular}

\section{DISCUSSION}

In the current study we demonstrated that the use of a fixed size PTFE band for annuloplasty while repairing degenerative MR provided satisfactory early results, which were comparable to the use of commercial mitral rings.

Annuloplasty is an integral part of mitral repair. Beyond the initial works of the Carpentier group (1), annuloplasty seems to reinforce posterior leaflet repairs, prevent further annular dilatation, and increase the area of coaptation during valve closure. Thus, adding to the durability of the repair ${ }^{(2,3)}$. Other studies have demonstrated that the lack of annuloplasty during mitral repair was an independent predictor of recurrence of significant MR and late reoperation (11, 12). However, there is little agreement on the ideal annuloplasty device. The debate continues on the merits of using complete versus partial rings, flexible versus rigid rings, flat versus three-dimensional ones, with no conclusive evidence in favor of absolute superiority of any of the specific types of commercial rings available ${ }^{(4,5,6,13)}$. In the midst of this lack of consensus, various working groups have started exploring the use of homemade alternatives using biological or prosthetic material, with two objectives in mind: decreasing cost and increasing simplicity of the procedure. Annuloplasty bands fashioned with the use of autologous pericardium were tried, with some authors demonstrating satisfactory long-term results ${ }^{(9)}$. The same group however had reported earlier a degree of calcification affecting these pericardial bands, which seemed to increase gradually over the years, although with no short-term adverse effects on the repaired valves. Other authors found the use of pericardial bands to negatively impact the durability of the repair and advocated the use of prosthetic bands ${ }^{(\mathbf{1 5})}$. Jeong et al. ${ }^{(\mathbf{1 6})}$ showed satisfactory results using Dacron strips, however the use of PTFE was more commonly reported, probably because of its stronger substance providing more stabilization for the posterior mitral annulus $(\mathbf{5 , 7 , 8 )}$.

In all the previously mentioned studies, authors used different methods to determine the size of the annuloplasty device used. Methods for sizing vary widely even among commercial rings, with improper sizing carrying the potential for serious complications (17). Prior pathologic studies showed that the normal adult mitral annular circumference should be around 10 $\mathrm{cm}$, with a ratio of $1: 2$ between the anterior intertrigonal part and the posterior portion of the annulus ${ }^{\mathbf{1 8} \text {, }}$ 19). Moreover, cardiac size and mitral annular size were previously shown not to always correlate with body surface area ${ }^{(20,21)}$. Thus, a posterior band with a length of $6-6.5 \mathrm{~cm}$ should bring the posterior annulus to nearly normal length. We chose the upper limit of this range to avoid undersizing. Brown $\boldsymbol{e t}$ al. ${ }^{(22)}$ previously reported the use of such a standard-size $(63 \mathrm{~mm})$ flexible posterior band with satisfactory results at 5-years follow-up. Although, our patients seemed to be of lesser height and weight, this did not seem to impact the transvalvular gradients when an almost similar length band was used. Similar to their findings, the use of this single-sized band was not associated with any elevated gradients across the mitral valve or with increased incidence of significant MR during the follow-up period. Compared to their report our patients seemed to be referred for surgery at a later stage, as evidenced by a higher incidence of pulmonary hypertension and atrial fibrillation. Moreover in their report, unlike the current study, they excluded all patients who underwent any concomitant procedures at the time of mitral repair. This may explain the higher early mortality in our study. 
The use of a single-sized band carries two main advantages. Firstly it decreases the cost of the procedure, which is an important factor in our settings with relatively limited financial resources. Second, it renders the procedure simpler, skipping the sizing as well as the placement of the anterior annular sutures. This is all achieved without jeopardizing the quality or the durability of the repair.

The limitations of our study included its retrospective nature, as well as the relatively small number of patients and the relatively short follow-up period. Longer follow-up of these patients is underway. Additionally, there are probably limits to the fixed length we used depending on the patient's or cardiac size. Our study did not explore these limits.

\section{CONCLUSION}

The use of a fixed size PTFE band for annuloplasty in degenerative mitral disease showed satisfactory results while potentially adding to the simplicity of the procedure and decreasing its cost. Further studies with longer follow-up are needed to confirm the durability of mitral repair using this technique.

\section{Financial support and sponsorship: Nil.}

Conflict of interest: Nil.

\section{REFERENCES}

1. Carpentier A (1969): Reconstructive valvuloplasty. A new technique of mitral valvuloplasty. Presse Med., 77: 251-53.

2. DiBardino D, EIBardissi A, McClure $\mathrm{R}$ et al. (2010): Four decades of experience with mitral valve repair: analysis of differential indications, technical evolution, and long-term outcome. J Thorac Cardiovasc Surg., 139: 76-83.

3. Gillinov A, Tantiwongkosri $\mathrm{K}$, Blackstone $\mathbf{E}$ et al. (2009): Is prosthetic anuloplasty necessary for durable mitral valve repair? Ann Thorac Surg., 88: 76-82.

4. Chang B, Youn Y, Ha J et al. (2007): Long-term clinical results of mitral valvuloplasty using flexible and rigid rings: A prospective and randomized study. J Thorac Cardiovasc Surg., 133: 995-1003.

5. Chee T, Haston R, Tago A et al. (2008): Is a flexible mitral annuloplasty ring superior to a semi-rigid or rigid ring in terms of improvement in symptoms and survival? Interact Cardiovasc Thorac Surg., 7 (3): 477-84.

6. Bogachev-Prokophiev A, Afanasyev A, Zheleznev S et al. (2017): Mid-term results of mitral valve repair using flexible bands versus complete rings in patients with degenerative mitral valve disease: a prospective, randomized study. J Cardiothorac Surg., 12: 113-22.

7. Warinsirikul W, Mokarapong P, Sangchote S et al. (1999): Midterm results of mitral valve repair with homemade annuloplasty rings. Ann Thorac Surg., 67: 6366.
8. Bezon E, Khalifa A, Choplain J et al. (2006): Homemade expanded-polytetrafluoroethylene flexible mitral annuloplasty ring. Eur J Cardiothorac Surg., 29 (2): 251-52.

9. Miura T, Obase K, Matsumaru I et al. (2020): Very long-term outcomes of twisted auto-pericardial mitral annuloplasty. Gen Thorac Cardiovasc Surg., 68 (10): 1113-18.

10.David T, Ivanov J, Armstrong S et al. (2005): A comparison of outcomes of mitral valve repair for degenerative disease with posterior, andterior, and bileaflet prolapse. J Thorac Cardiovasc Surg., 130: 124249.

11. Masiano F, Caldarola A, Blasio A et al. (2003): Midterm results of edge-to-edge mitral valve repair without annuloplasty. J Thorac Cardiovasc Surg., 126: 1987-97.

12.Suri R, Schaff H, Dearani J et al. (2006): Survival advantage and improved durability of mitral repair for leaflet prolapse subsets in the current era. Ann Thorac Surg., 82: 819-26.

13.Jamieson W (2006): Advanced technologies for cardiac valvular replacement, transcatheter innovations and reconstructive surgery. Surg Technol Int., 15: 149-87.

14. Miura T, Eishi K, Sakamato I et al. (2012): Timedependent change in fresh autologous pericardium applied for posterior mitral annuloplasty: degree of calcification and its influence on the repaired mitral valve. Gen Thorac Cardiovasc Surg., 60: 334-340.

15. Bevilacqua S, Cerillo A, Gianetti J et al. (2003): Mitral valve repair for degenerative disease: is pericardial posterior annuloplasty a durable option? Eur J Cardiothroac Surg., 23: 552-59.

16.Jeong D, Lee H, Kim W et al. (2011): Long-term echocardiographic follow-up after posterior mitral annuloplasty using a vascular strip for ischemic mitral regurgitation: Ten-years of experience at a single center. $\mathbf{J}$ Korean Med Sci., 26: 1582-1590.

17. Bothe W, Miller D, Doenst T (2013): Sizing for mitral annuloplasty: where does science stop and voodoo begin? Ann Thorac Surg., 95 (4): 1475-83.

18. Oslon L, Subramanian R, Ackermann D et al. (1987): Surgical pathology of the mitral valve: a study of 712 cases spanning 21 years. Mayo Clin Proc., 62: 22-34.

19. Hueb A, Jatene F, Moreira L et al. (2002): Ventricular remodeling and mitral valve modifications in dilated cardiomyopathies: new insights from anatomic studies. J Cardiovasc Surg., 124: 1216-24.

20. Mathew R, Gaasch W, Guilmette N et al. (2003): Anthropometric normalization of left ventricular size in chronic mitral regurgitation. Am J Cardiol., 91: 762-4.

21. Okamoto H, Itoh Y, Nara Y (2007): Geometric analysis of the anterior mitral leaflet and mitral valve orifice in cadaveric hearts. Circ J., 71: 1794-9.

22. Brown M, Schaff H, Li Z et al. (2009): Results of mitral valve annuloplasty with a standard-sized posterior band: is measuring important? J Thorac Cardiovasc Surg., 138: 886-91. 